\title{
CONF- $9609104--2$
}

\section{Amorphous Rare Earth Magnet Powders}

\author{
C.H. Sellers, D. J. Branagan, and T.A. Hyde \\ Idaho National Engineering Laboratory, POB 1625, \\ Idaho Falls, ID 83415-2211, USA
L. H. Lewis
Department of Applied Science, Brookhaven National Laboratory, Upton, NY 11973-5000, USA \\ V. Panchanathan \\ Magnequench International \\ 6435 S. Scatterfield Rd., Anderson, IN 46013, USA
}

\begin{abstract}
Gas atomization (GA) processing does not generally have a high enough cooling rate to produce the initial amorphous microstructure needed to obtain optimal magnetic properties in $\mathrm{RE}_{2} \mathrm{Fe}_{14} \mathrm{~B}$ alloys. Phase separation and an underquenched microstructure result from detrimental $\alpha$-Fe precipitation, and the resulting magnetic domain structure is very coarse. Additionally, there is a dramatic dependence of the magnetic properties on the cooling rate (and therefore the particle size) and the powders can be sensitive to environmental degradation. Alloy compositions designed just for GA (as opposed to melt spinning) are necessary to produce an amorphous structure that can be crystallized to result in a fine structure with magnetic properties which are independent of particle size. The addition of titanium and carbon to the melt has been found to change the solidification process sufficiently to result in an "overquenched" state in which most of the powder size fractions have an amorphous component. Crystallization with a brief heat treatment produces a structure which has improved magnetic properties, in part due to the ability to use compositions with higher Fe contents without $\alpha$-Fe precipitation. Results from magnetometry, magnetic force microscopy, and $x$-ray analyses will be used to contrast the microstructure, domain structure, and magnetic properties of this new generation of amorphous powders with their multiphase predecessors.
\end{abstract}

\section{Introduction}

For many years gas atomization (GA) has been examined as a processing route for the production of rare earth permanent magnet materials such as $\mathrm{Nd}_{2} \mathrm{Fe}_{14} \mathrm{~B}(2-14-1) .^{1-4}$ Similar to the commercially viable technique of melt spinning, GA involves rapid solidification from the melt and can result in a homogenous microstructure for fine powders. As in the case of melt spun ribbons, gas atomized powders are magnetically isotropic, potentially making them suitable for isotropic bonded and hot pressed magnets. Previous efforts to produce powders with suitable properties have been plagued by a numerous problems which prevent their use in bonded magnets. Analysis of the phase diagram indicates that the 2-14-1 phase is a line compound and congruent solidification requires cooling rates that are typically higher than those normally experienced during gas atomization. Atomization of alloy compositions similar to those used in melt spinning results in the precipitation of 
$\alpha$-Fe because of the inadequate cooling rate. By using higher rare earth concentrations, powders with improved magnetic properties can be produced but these have a coarse, multiple phase microstructure in all but the finest powders. A homogeneous microstructure is achieved in melt spun ribbons by cooling the melt at a rate sufficient to produce a structure which is at least partially amorphous, and then heat treated to yield a microcrystalline structure with optimal magnetic properties. This level of cooling may be realized in GA only for extremely fine $(<5 \mu \mathrm{m})$ powders, prompting efforts to design atomization facilities which specifically produce such small powders. This route may result in a product which is susceptible to corrosion (because of the high surface to volume ratio), dangerous to handle (because of the pyrophoric nature of rare earths), and unfamiliar in flow characteristics to magnet processors. An alternate approach to improving these materials is to alter the solidification characteristics of the melt to result in a fine microstructure in larger sized particles.

\section{Experimental}

Rare earth alloy compositions near the composition $\mathrm{RE}_{2} \mathrm{Fe}_{14} \mathrm{~B}$ were prepared from commercial grade materials by induction melting into an ingot. Several weight percent of $\mathrm{Ti}$ and $\mathrm{C}$ were also incorporated into some alloys at this point to alter the solidification characteristics ${ }^{5}$. The ingot was broken up and induction melted (to a superheat of $1450^{\circ} \mathrm{C}$ ) in the crucible of a small ( $<7 \mathrm{~kg}$ capacity) gas atomizer using a close coupled nozzle configuration and $\mathrm{He}$ (generally) as a cooling gas. The powder size distribution was characterized by sonic sieving in air. Magnetic properties of powders were determined using a vibrating sample magnetometer (VSM) after immobilization in wax and saturation in a capacitive magnetizer (6.5 Tesla field). No demagnetization corrections were used. Magnetic Force Microscopy (MFM) was done with a Digital Instruments NanoScope III in the tapping mode. $\mathrm{X}$-ray analysis was made using $\mathrm{Cuk}_{\alpha}$ radiation. Powders were heat treated in an infrared vacuum furnace at $10^{-6}$ torr.

\section{Results and Discussion}

\subsection{Atomized Fully Crystalline Powders}

Over a period of several years many different alloy formulations have been atomized to determine the effect of composition, processing conditions, and atomizing gas on the powder microstructure and magnetic properties. Figure 1 illustrates the microstructures characteristic of alloys atomized with a commercial melt spinning composition (30.1 wt\% Nd, 69.0 wt\% $\mathrm{Fe}, 0.91 \mathrm{wt} \% \mathrm{~B}$ ) with a detailed view of Fe microsegregation. The dark features in

Fig. 1a) are properitectic $\alpha$-Fe that formed due to an inadequate cooling rate, locally depleting the alloy of $\mathrm{Fe}$ and resulting in the development (Fig. 1b) of rare earth rich regions (light areas). In the backscattered electron image the desired 2-14-1 phase appears gray. The second quadrant of the magnetic hysteresis loop for this material has a poor shape due to the presence of the soft magnetic $\mathrm{Fe}$ and heat treatment does not result in significant improvements. There is a strong dependence of the magnetic properties on the powder size due to the effect of cooling rate on the microstructure, but maximum energy products do not exceed $1.5 \mathrm{MGOe}$ after heat treatment $\left(10\right.$ minutes at $650^{\circ} \mathrm{C}$ ). 


\section{DISCLAIMER}

Portions of this document may be illegible in electronic image products. Images are produced from the best available original document. 


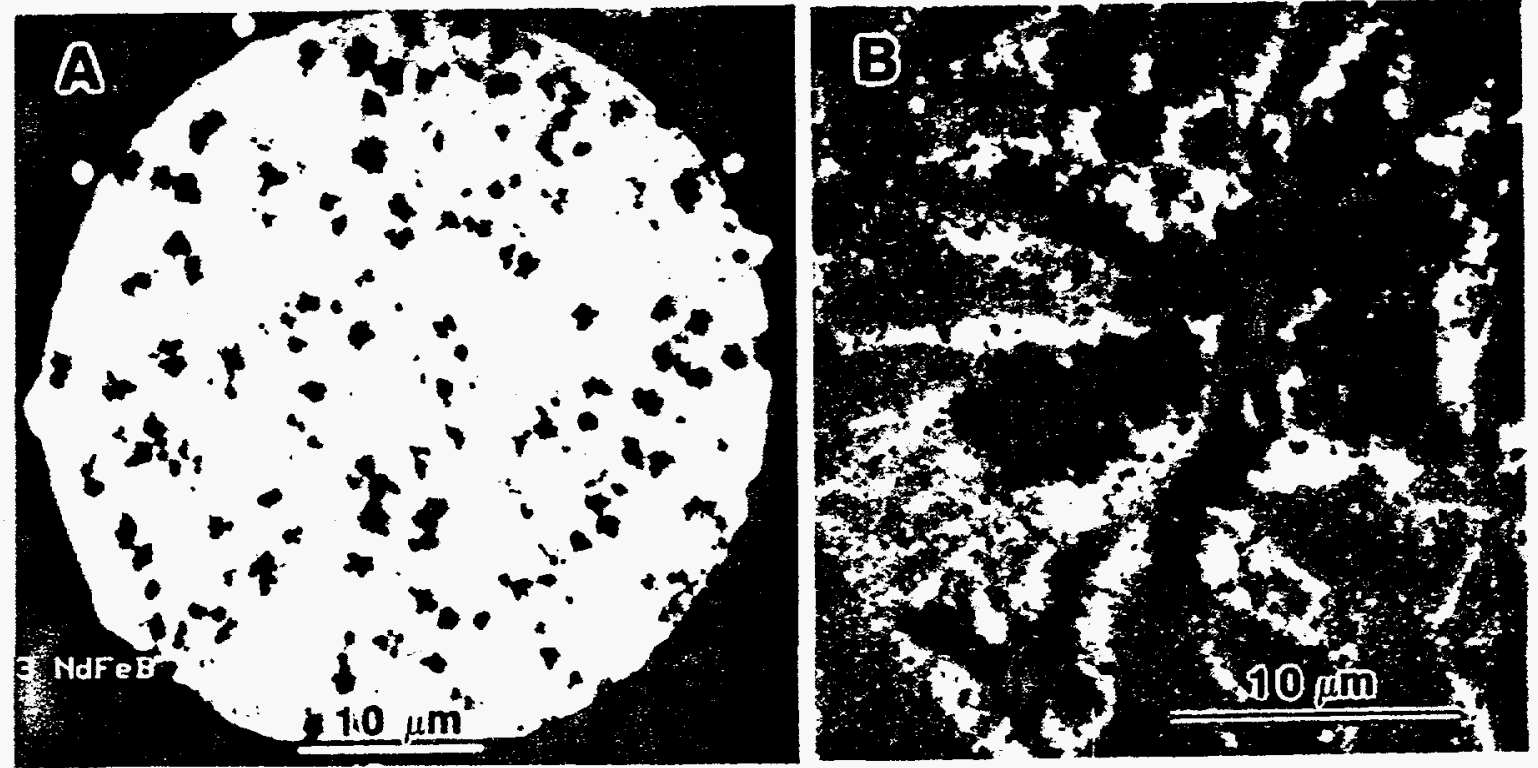

Figure 1. Scanning electron microscope images of powder cross sections, a) a commercial melt spinning alloy and b) magnified view of Fe segregation.

Figure 2 illustrates the microstructure of a rare earth rich composition $(31.5 \mathrm{wt} \% \mathrm{Nd}, 3.1$ wt\% Dy, 64.2 wt\% Fe, $1.15 \mathrm{wt} \% \mathrm{~B}$ ) characteristic of past atomization efforts at other laboratories. 6,7
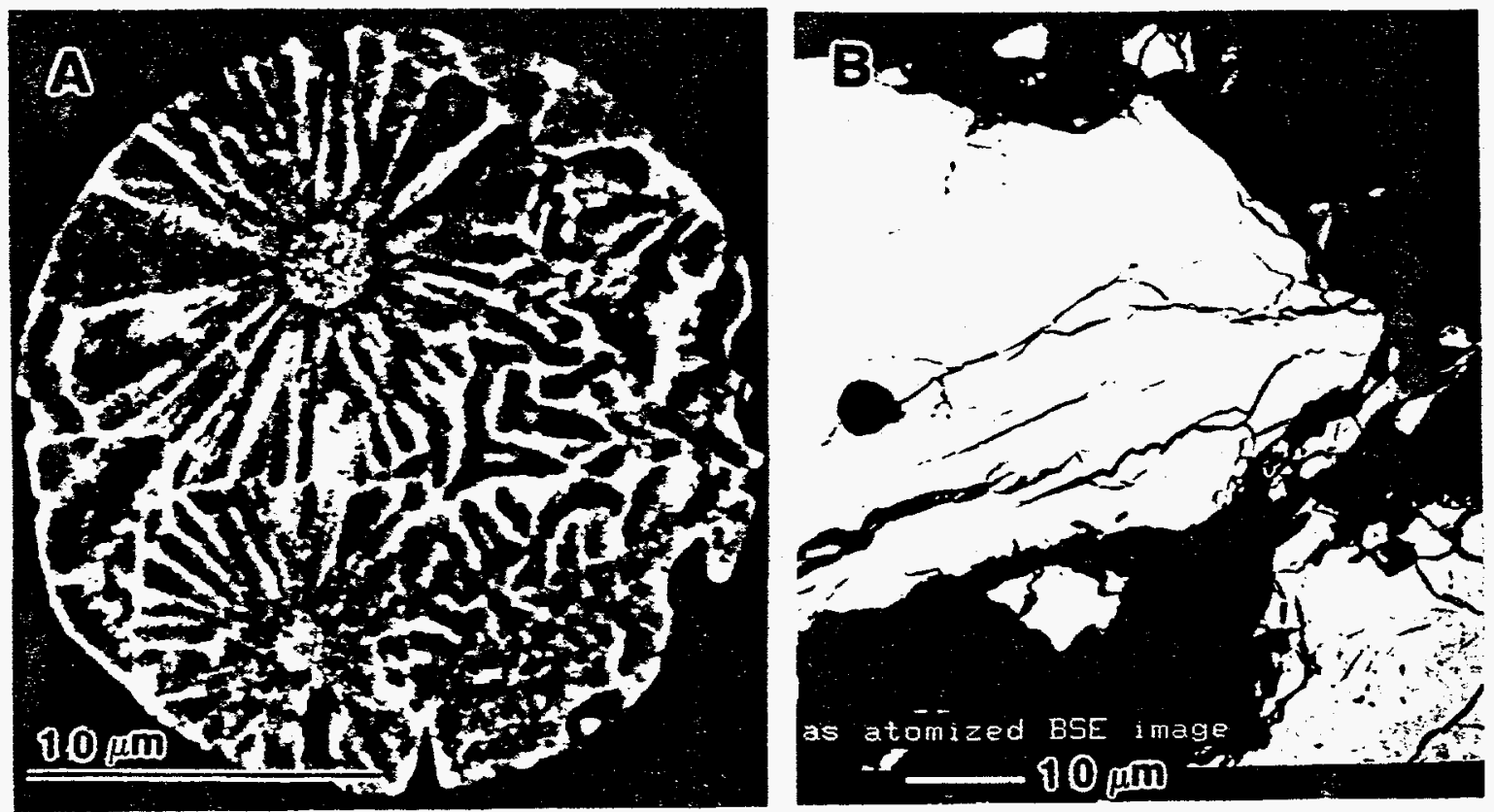

Figure 2. Scanning electron microscope images of powder cross sections of a rare earth rich composition often used for gas atomization; atomized with a) $\mathrm{He}$ gas and b) $\mathrm{N}_{2}$ gas. 
Use of alloys with excess rare earths (compared to commercial alloys that are closer to the stoichiometric composition) prevents the precipitation of $\alpha$-Fe but results in a significant volume fraction of a rare earth-rich phase (unidentifiable with by $\mathrm{x}$-ray diffraction, but probably with the eutectic composition) which can be expected to dilute the magnetic properties volumetrically. The as-atomized properties of the powders are essentially independent of the atomizing gas, despite the differences in powder morphology (apparent in Figure 2), and are considerably better than those found in lower RE compositions 8.9 . There is still a considerable powder size dependence of the magnetic properties, but this is reduced following heat treatment. Coercivities as high as $20 \mathrm{kOe}$ and energy products of 9 MGOe (smallest particles only) can be achieved using this alloying strategy. From experience with melt spun ribbons, heat treatment of an underquenched 2-14-1 state does not result in a significant improvement in magnetic properties. Gas atomized powders with a rare earth rich composition have been determined to be underquenched (except possibly in the case of the very finest particles) from the lack of evidence for amorphous fractions using $x$ ray diffraction and differential thermal analysis (DTA). Unlike ribbons, underquenched powders can be effectively heat treated to achieve relatively high levels of coercivity $\left(\mathrm{H}_{\mathrm{Ci}}\right)$, remanence $\left(\mathrm{B}_{\mathfrak{r}}\right)$, and maximum energy product $\left(\mathrm{BH}_{\max }\right)$. The general differences between the as-quenched/atomized and heat treated $\mathrm{BH}_{\max }$ for melt spun and gas atomized powders are illustrated in Figure 3. The reason for these differences appears to be related to the lack of homogeneity in melt spun ribbons produced at slow wheel speeds and is the subject of a separate publication. 10

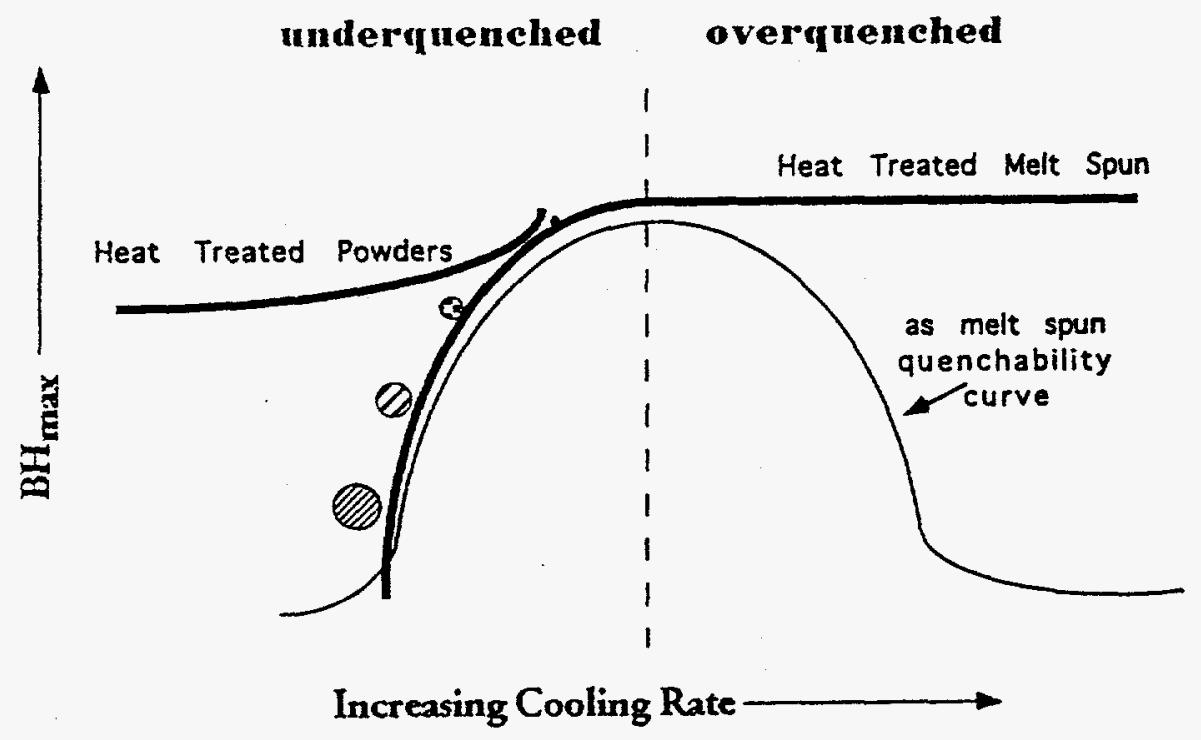

Figure 3. Schematic description of the as-atomized/quenched and heat treated $\mathrm{BH}_{\max }$ for gas atomized powders and melt spun ribbons. The spheres indicate relative sizes of gas atomized powders; their positions represent their approximate cooling rate and corresponding $\mathrm{BH}_{\max }$.

Figure 4 shows the second quadrant of the hysteresis loop for powders with the compositions of those shown in Figures 1 and 2, illustrating the effect of composition, powder size, and heat treatment on the loop shape, $\mathrm{H}_{\mathrm{ci}}, \mathrm{B}_{\mathrm{r}}$, and $\mathrm{BH}_{\max }$. The powders appear nominally environmentally stable, suffering no loss in properties after exposure to normal laboratory conditions for 3 years. Auger electron spectroscopy indicates that a natural oxide layer is developed on the surface from trace impurity gases during atomization, such that no special handling or coating is necessary. 


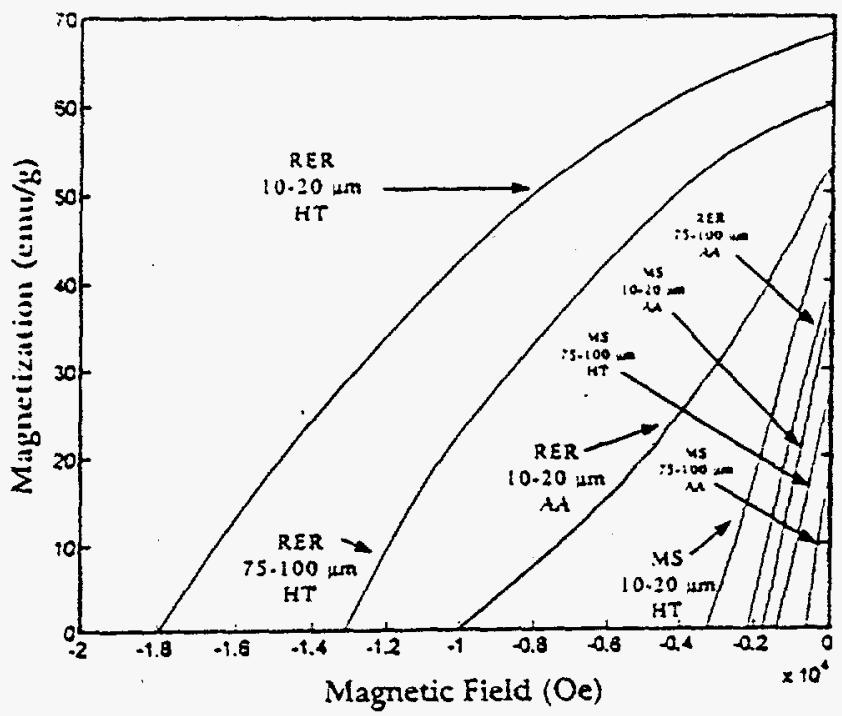

Figure 4. Demagnetization curves for coarsely microstructured powders (RER = rare earth rich alloy, MS $=$ melt spinning alloy, $\mathrm{AA}=$ as-atomized, and $\mathrm{HT}=$ heat treated). The density of RER is 7.33 and that of MS is $7.5 \mathrm{~g} / \mathrm{cm}^{3}$.

While maximum energy products in the vicinity of 7-9 MGOe (depending on the powder size) do not closely approach those of melt spun ribbon ( +12 MGOe), the potential advantages of a spherical particle morphology led to attempts to produce bonded magnets from the rare earth rich powders. Figure 5 illustrates that when bonded magnets are formed from heat treated powders the energy product decreases substantially. The loop shape is found to have reverted back to that of the pre-annealed state.

Experiments to simulate the bonding process were performed on the pow-

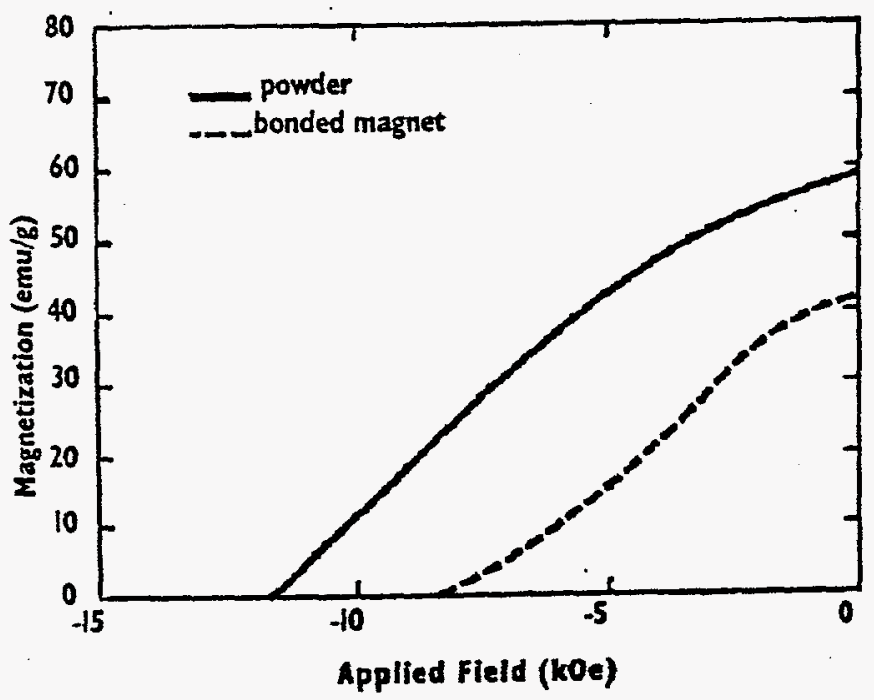

Figure 5. Comparison of the demagnetization curves of a) rare earth rich powder with $\mathrm{BH}_{\max }=7 \mathrm{MGOe}$, and b) $a$ bonded magnet made from this powder with a resulting $\mathrm{BH}_{\max }=2$ MGOe. ders using a curing treatment in air at $170^{\circ} \mathrm{C}$ for several minutes, indicate that elevated temperature instability is responsible for the reduction in $\mathrm{B}_{\mathrm{r}}$, $\mathrm{BH}_{\max }$, and $\mathrm{H}_{\mathrm{ci}}$. All 3 can be returned to their original values if the degraded powder is re-annealed at $650^{\circ} \mathrm{C}$ for 10 minutes, suggesting that this phenomena is surface in nature rather than due to bulk oxidation. Examination of the magnetic domain structure using MFM indicates that the domain size is very large and correlated with the coarse microstructure; it seems that the degradation mechanism is related to the reversal of the large surface domains which detrimentally effect the interior domains. Clearly, gas atomized powder produced from rare earth rich alloys is not suitable for the fabrication of bonded magnets. 


\subsection{Atomized Powders with an Amorphous Fraction}

In order to produce powders which are suitable for use in bonded magnets, an overquenched structure similar to that produced in melt spun ribbons may be required. Past work on alloy modifications for melt spun ribbons to increase their "quenchability" has indicated that the addition of key transition metals and carbon to the atomizer melt changes the characteristics of the solidification process significantly. 5 These additions are soluble in the melt but insoluble in the solid powders, precipitating as transition metal carbides. Titanium and carbon additions amounting to 3 weight percent each were added to a commercial melt spinning alloy $(30.1 \mathrm{wt} \% \mathrm{Nd}, 69.0 \mathrm{wt} \% \mathrm{Fe}, 0.91 \mathrm{wt} \% \mathrm{~B})$ for evaluation of the applicability of this methodology to gas atomization. Upon atomization, it is found that finer powder particles than usual are formed, perhaps due to changes in the physical characteristics of the melt. The particle size distribution, as determined from sieve analysis, indicates a mean powder size of 14 microns. The powder microstructure has initially been determined by x-ray diffraction, differential thermal analysis, and SEM analysis with backscattered electrons. The diffraction patterns shown in Figure 6 for several as-atomized powder sizes indicate that the finest powders are completely amorphous while larger particles are partially amorphous - even the 75 to $100 \mu \mathrm{m}$ size range has some glassy fraction. DTA analysis indicates that there is a glass to crystalline transition at $615^{\circ} \mathrm{C}$ in particles up to $100 \mu \mathrm{m}$ in diameter. The SEM image of a larger particle shows that the microstructure is quite homogeneous, with only traces of a high rare earth phase (light spots).
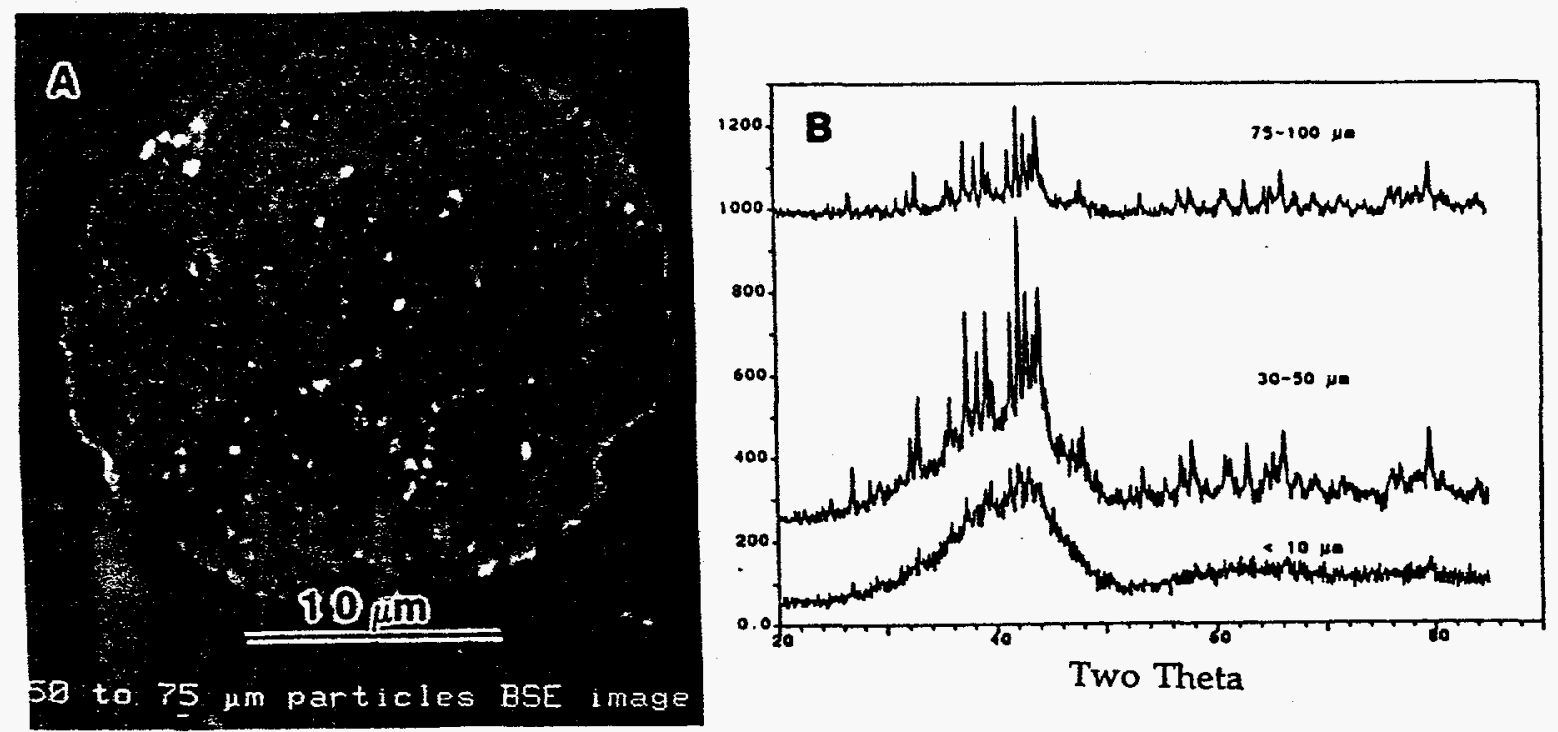

Figure 6. Microstructure of powder particles, a) SEM image showing homogeneity in a 50-75 $\mu \mathrm{m}$ particle and $b$ ) $x$-ray diffraction scans of several powder size ranges indicating the presence of an amorphous fraction.

Magnetic measurements on the as-atomized powders as a function of particle size indicate that there is a dramatic change in the particle size dependence of the magnetic properties (Figure 7). While rare earth rich alloys show an improvement in hard magnetic properties as the cooling rate increases, the new alloys modified with $\mathrm{TiC}$ exhibit soft magnetic 
properties (with coercivities of 100 Oe for the smallest particles). As the powder size increases a maximum in $\mathrm{BH}_{\max }$ is reached before decreasing again for the largest particles. This is consistent with the production of completely amorphous powders in the finer size fractions, particles with an amorphous + microcrystalline structure up to the $75-100 \mu \mathrm{m}$ size range, and particles with an underquenched structure in the largest size range. This "bell" shaped dependence of the magnetic properties upon the cooling rate (via the powder size) is very reminiscent of the behavior observed in melt spun ribbons as the cooling rate is changed (by altering the wheel speed, see Figure 3 ).
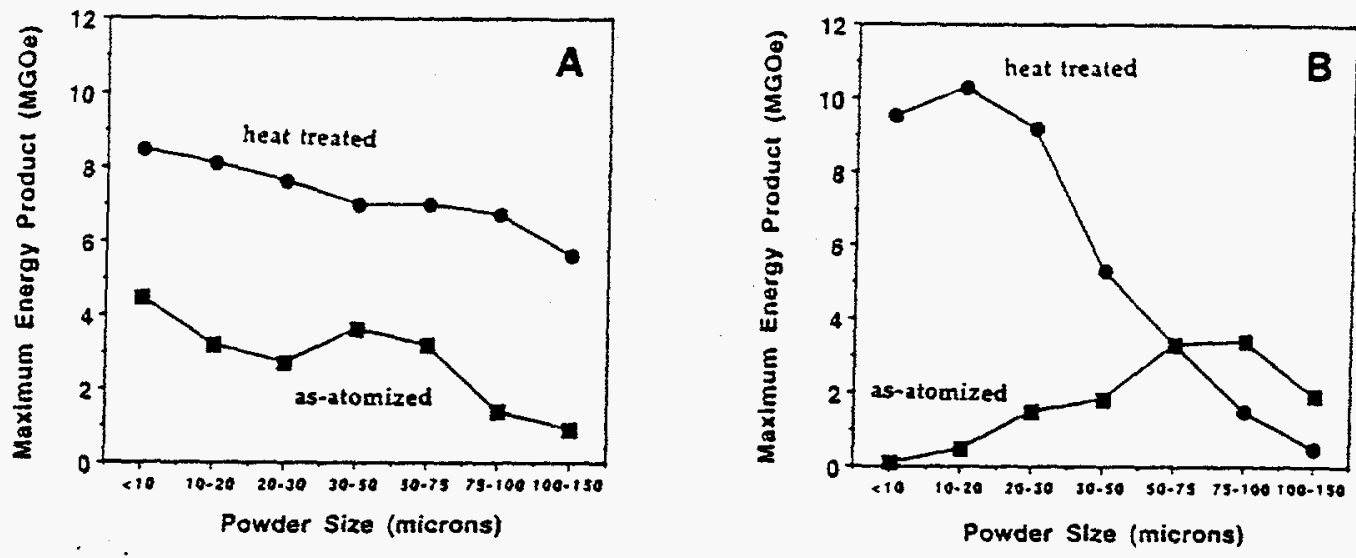

Figure 7. Particle size dependence of the as-atomized and heat treated $\mathrm{BH}_{\max }$ for a) a rare earth rich alloy and b) a TiC modified alloy.

Just as in overquenched (amorphous or partially amorphous structure) melt spun ribbons, as-atomized powders which are significantly overquenched $(<30 \mu \mathrm{m})$ are easily crystallized to the optimal structure by heat treatment. These attain energy products in excess of 10 MGOe, higher than was achieved previously for such a large weight fraction of a single atomization batch. The ability to use alloy compositions which are lower in rare earth content (and consequently, higher in $\mathrm{Fe}$ ) is largely responsible for the increase in $\mathrm{B}_{\mathrm{r}}$ and $\mathrm{BH}_{\max }$. A much higher annealing temperature ( $800-850^{\circ} \mathrm{C}$ for 10 minutes) is needed to optimally crystallize this material, but they are much less sensitive to the heat treatment temperature than past powders; high rare earth content powders and melt spun ribbons have only a narrow temperature range over which they can be magnetically optimized, probably due to problems with grain growth at higher temperatures. We are investigating whether the fine $\mathrm{TiC}$ precipitates formed upon crystallization promote high temperature ( $900^{\circ} \mathrm{C}$ and above) magnetic property stability by preventing grain growth and/or pinning domain boundaries. Powders made from alloys with $\mathrm{TiC}$ are different from previous ones in that the larger particles (those in an underquenched state) do not respond well to heat treatment. This is similar to the situation seen in underquenched melt spun ribbons but the larger powder particles do not have the grossly inhomogeneous microstructure seen in slowly cooled ribbons (due to exodus from the wheel surface prior to complete solidification). Fortunately, only a small fraction of the material produced is in the underquenched condition. Figure 8a) compares the demagnetization curves of the basic commercial melt spun ribbon composition after heat treatment after 1) preparation by melt spinning, b) gas 
atomization after modification with $\mathrm{Ti}+\mathrm{C}$.and c) gas atomization without modification. While the gas atomized modified alloy has a lower $\mathrm{H}_{c i}$ than the melt spun ribbon, $\mathrm{B}_{\mathrm{r}}$ is unchanged, and $\mathrm{BH}_{\max }$ is quite high. Figure $8 \mathrm{~b}$ ) contrasts the performance of the modified powder when incorporated into a bonded magnet using 5 wt $\%$ epoxy standard curing conditions. Most notable is the fact that the bonded magnet curve shape is unchanged from that of the powder and $\mathrm{H}_{\mathrm{Ci}}$ remains unchanged. $\mathrm{B}_{\mathrm{r}}$ is decreased as would be expected due to the decreased density.

\section{A}

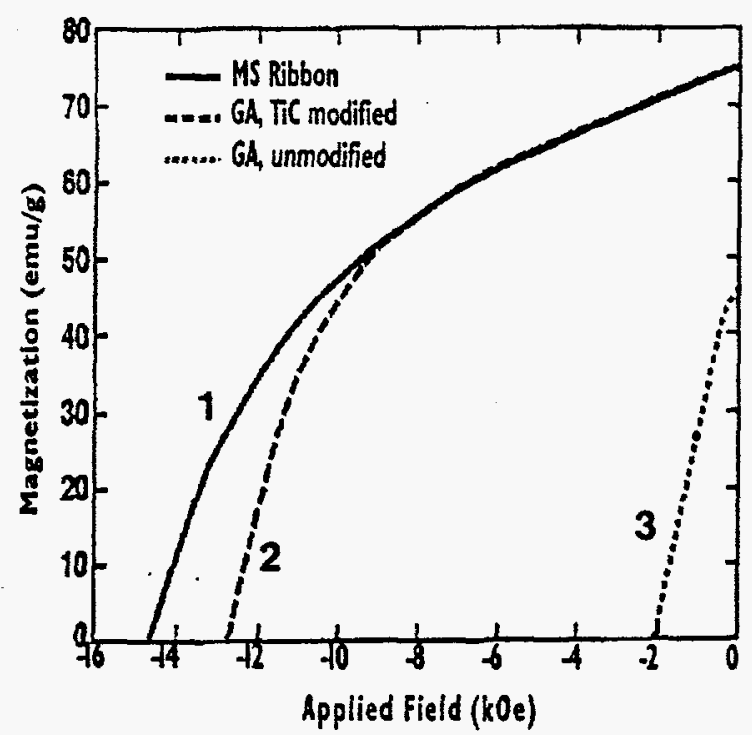

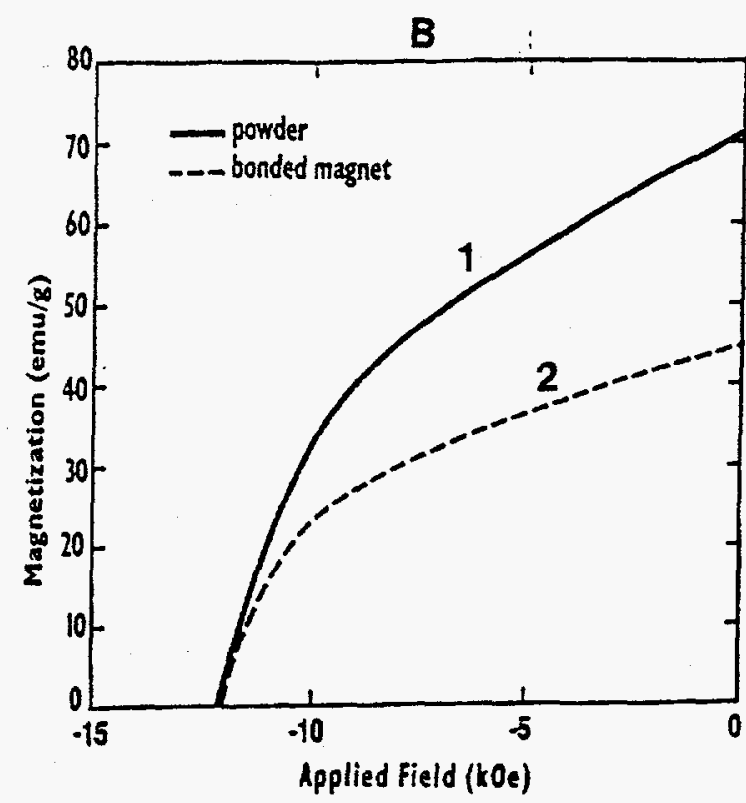

Figure 8. A) demagnetization curves of 1) meit spun ribbon, 2) gas atomized powder with $T i$ and $C$ added to this composition, and 3) gas atomized powder without TiC. B) demagnetization curves of 1) $\mathrm{Ti}+\mathrm{C}$ modified alloy powders and 2) a bonded magnet made from this powder using 5 wt\% epoxy. The density of the $\mathrm{TiC}$ modified powder is $7.5 \mathrm{~g} / \mathrm{cm}^{3}$.

Besides the obvious differences in the microstructure between the high rare earth composition powders and the ones modified with $\mathrm{Ti}+\mathrm{C}$, an important clue to the differences in their behavior upon incorporation into a bonded magnet form can be seen from their domain structure. Figure 9 compares the MFM images of powder particle cross sections of two alloys representative of these two distinct approaches. The domain structure (the microscope actually measures the force gradient and not the stray magnetic fields, as is done in many domain imaging techniques) of the rare earth rich powder is distinctly correlated with the coarse, dendritic solidification microstructure shown in Figure 1a), with one of the solidification nucleation sites located just above the center of the particle. Each primary dendrite arm is presumably a single crystal and contains many large (approximately $1 \mu \mathrm{m}$ ) domains arranged within it to minimize the demagnetization energy. The high rare earth interdendritic phase is not clearly evident but it decouples domains within adjacent dendrites. The MFM image of the modified powder particle shows a much smaller domain size and a uniform domain structure that has an unknown amount of correlation with the very fine microstructure. This domain structure resembles very closely that of optimally quenched melt spun ribbons ${ }^{11}$ and appears to be responsible for the good performance of bonded magnets made from the new materials. 


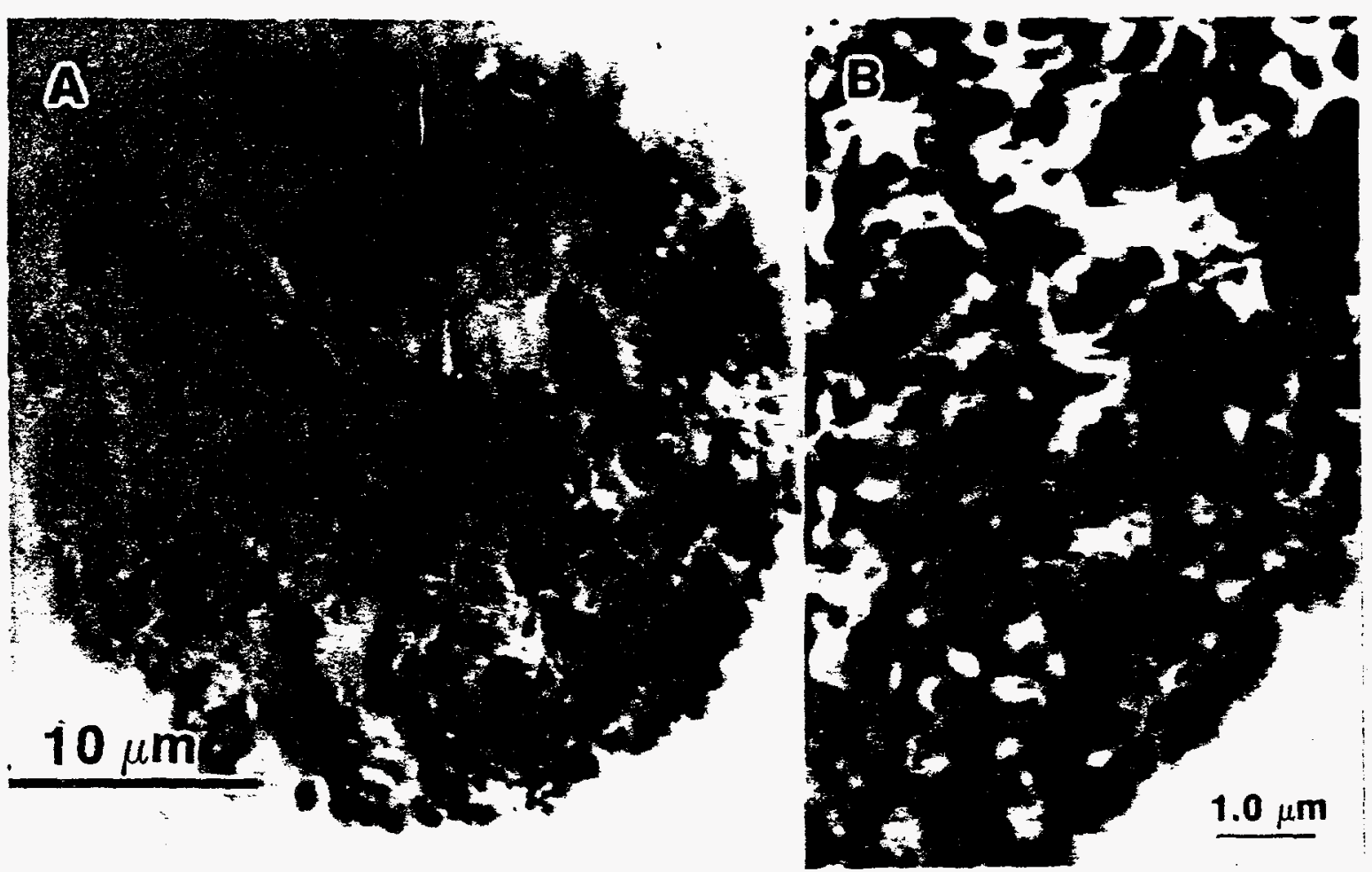

Figure 9. Magnetic Force Microscope images of a) a rare earth rich alloy powder and b) a TiC modified alloy.

\section{Summary and Conclusions}

A comparison between gas atomization of 2-14-1 based alloy compositions shows that this processing technique is generally sensitive to the composition due to the rapid cooling rate necessary to produce underquenched material. Commercial melt spinning alloy formulations develop properitectic $\alpha-\mathrm{Fe}$, yielding poor as-atomized magnetic properties and little improvement upon heat treatment. The traditional solution has been to use alloy compositions which have a high rare earth concentration, resulting in coarse domain and microstructures and poor performance in bonded magnets. By the addition of $\mathrm{Ti}$ and $\mathrm{C}$ to the melt spinning alloy composition, powders are produced with a markedly different structure and improved magnetic properties. Powders with a diameter less than $30 \mu \mathrm{m}$ have a very fine microstructure, contain an amorphous component, and can be heat treated to obtain maximum energy products in excess of $10 \mathrm{MGOe}$. Particles up to $100 \mu \mathrm{m}$ have an amorphous fraction and a microstructure which is not particularly coarse, but cannot yet be heat treated to achieve adequate values of $\mathrm{BH}_{\max }$. The new generation is an improvement over the old not so much in its enhanced energy product, but in its radically improved domain and microstructure. The ability to produce bonded magnets from gas atomized powders is now possible because of improved thermal stability and the corrosion resistance developed due to a more homogeneous structure. Work is still needed to increase the maximum energy product - higher $\mathrm{Fe}$ compositions, the addition of minor alloying elements, and an improved understanding of the effects of TiC upon the solidification behavior of 2-14-1 based alloys should make further improvements possible. The excellent high temperature stability of the alloys described here may also lead to improvements in bulk magnets processed by hot deformation techniques. 


\section{Acknowledgments}

The authors would like to acknowledge the invaluable assistance of J. Burch, M. Hankins, and T. Morris at the INEL. Research and discussions with Advanced Surface Microscopy, Inc. was essential for the MFM work. INEL work was supported through the Long-Term Research Initiative Program and DOE Division of Basic Energy Science under DOE Idaho Operations Office Contract DE-AC07-94ID13223. Research performed at BNL was done under the auspices of the U.S. Department of Energy, Division of Materials Sciences, Office of Basic Energy Sciences under contract No. DE-AC02-76CH00016.

\section{References}

1. M. Yamamoto, A. Inoue, and T. Masumoto, Met. Trans. A 20A, 5 (1989).

2. C.J. Williams, E.J. Dulis, and F.S. Snyder, U.S. Patent 4,994,109, "Method for Producing Permanent Magnet Alloy Particles for Use in Producing Bonded Permanent Magnets", Feb. 19, 1991.

3. I.E. Anderson, B.K. Lograsso, and R.W. McCallum, Proceedings of the First International Conference on Processing of Materials for Properties, eds. H. Henein and T. Oki, . 645 (TMS Publications, 1993).

4. Z.S. Wronski, J. Appl. Phys. 69, 5507 (1991).

5. D.J. Branagan and R.W. McCallum, J. Magn. Magn. Mater. 146, 89 (1995).

6. K.S.V.L. Narasimhan and E.J. Dulis, U.S. Patent 4,585,473, "Method for Making Rare Earth Element Containing Permanent Magnets", April 29, 1986.

7. R.W. McCallum, K.W. Dennis, B.K. Lograsso, and I.E. Anderson, U.S. Patent 5,240,513, "Method of Making Bonded or Sintered Permanent Magnets", Aug. 31, 1993.

8. L. Henderson Lewls, C.H. Sellers, and V. Panchanathan, IEEE Trans. Mag. 31, 3641 (1995).

9. L.H. Lewis, C.H. Sellers, and V. Panchanathan, IEEE Trans. Magn., in press.

10. D.J. Branagan, T.A. Hyde, and C.H. Sellers, to be published.

11. D.J. Branagan, T.A. Hyde, C.H. Sellers, and L.H. Lewis, IEEE Trans. Magn., in press.

\section{DISCLAIMER}

This report was prepared as an account of work sponsored by an agency of the United States Government. Neither the United States Government nor any agency thereof, nor any of their employees, makes any warranty, express or implied, or assumes any legal liability or responsibility for the accuracy, completeness, or usefulness of any information, apparatus, product, or process disclosed, or represents that its use would not infringe privately owned rights. Reference herein to any specific commercial product, process, or service by trade name, trademark, manufacturer, or otherwise does not necessarily constitute or imply its endorsement, recommendation, or favoring by the United States Government or any agency thereof. The views and opinions of authors expressed herein do not necessarily state or reflect those of the United States Government or any agency thereof. 